\title{
Patient-reported outcome measures for masticatory function in adults: a systematic review
}

\author{
Yanpin Fan, Xin Shu, Katherine Chiu Man Leung and Edward Chin Man Lo*
}

\begin{abstract}
Objective: The aim of this systematic review was to critically evaluate the Patient-Reported Outcome Measures (PROMs) for masticatory function in adults.

Methods: Five electronic databases (Medline, Embase, Web of Science Core Collection, CINAHL Plus and APA PsycINFO) were searched up to March 2021. Studies reporting development or validation of PROMs for masticatory function on adults were identified. Methodological quality of the included studies was evaluated using the COnsensus-based Standards for the selection of health Measurement INstruments (COSMIN) risk of bias checklist. Psychometric properties of the PROM in each included study were rated against the criteria for good measurement properties based on the COSMIN guideline.
\end{abstract}

Results: Twenty-three studies investigating 19 PROMs were included. Methodological qualities of these studies were diverse. Four types of PROMs were identified: questions using food items to assess masticatory function (13 PROMs), questions on chewing problems (3 PROMs), questions using both food items and chewing problems (2 PROMs) and a global question (1 PROM). Only a few of these PROMs, namely chewing function questionnaire-Chinese, Croatian or Albanian, food intake questionnaire-Japanese, new food intake questionnaire-Japanese, screening for masticatory disorders in older adults and perceived difficulty of chewing-Tanzania demonstrated high or moderate level of evidence in several psychometric properties.

Conclusions: Currently, there is no PROM for masticatory function in adults with high-level evidence for all psychometric properties. There are variations in the psychometric properties among the different reported PROMs.

Trial Registration PROSPERO (CRD42020171591).

Keywords: Mastication, Chewing ability, Patient reported outcome measures, Epidemiology, Adult

\section{Background}

Masticatory difficulty or masticatory problem is prevalent in older adults worldwide [1-3]. Masticatory function has been found to be associated with physical activity level, disability, comorbidities and cognitive status [4]. A recent consensus report classified the

*Correspondence: edward-lo@hku.hk

Faculty of Dentistry, The University of Hong Kong, 1/F, Prince Philip Dental Hospital, 34 Hospital Road, Sai Ying Pun, Hong Kong, China methodologies for assessment of masticatory function into three types, namely direct objective assessment, indirect assessment and subjective assessment [5]. In direct objective assessment, masticatory function is evaluated by assessing a test material either after a predetermined number of chewing strokes (masticatory performance) or at the moment when the study participant feels the urge to swallow (swallowing threshold). In indirect objective assessment, masticatory function is evaluated by jaw kinematics, muscle activity, 
tongue or lip function, and saliva secretion. In subjective assessment, self-assessment of masticatory function is evaluated using questionnaires and interviews. A recent systematic review reported that none of the established objective assessments of masticatory function had strong evidence for all measurement properties and these assessments required sieves or digital image software [6].

Self-assessment of masticatory function uses patient-reported outcome measures (PROMs), mainly questionnaires. This has the advantage of assessing masticatory function from the person's perspective, taking into account adaptational and psychological factors. Some studies found there were correlations between self-assessment and objective assessment of masticatory function [7-9]. However, other researchers reported a lack of agreement between the subjective and the objective assessments of masticatory function [10, 11]. It should be noted that not all PROMs are created equal, and well-designed PROMs are needed to reveal the true masticatory function. Quality of the information collected and strength of the conclusion made depend on the properties of the instrument used in the study [12]. The methodological quality and psychometric properties of PROMs, such as content validity, structural validity, reliability, internal consistency and construct validity, are important aspects for the development or selection of a reliable and valid measurement tool $[13,14]$. It is important to use PROMs which have undergone rigorous psychometric testing to ensure the results obtained are valid and reliable. The COSMIN guideline was developed to enhance the quality of systematic review of PROMs [15-18].

In the past decade, a systematic review of all generic PROMs for adult dental patients [19] and a few systematic reviews of PROMs used in implant dentistry [20-22] were published. However, to the best of our knowledge, there is no systematic review of PROMs for assessing masticatory function. Therefore, based on the COSMIN guideline, this review aimed to identify PROMs that have been used in adults (population) for subjective assessment (type of instruments) of masticatory function (construct), and to evaluate the methodological qualities and psychometric properties (measurement properties of interest) of these PROMs.

\section{Methods}

This systematic review was registered in PROSPERO (Registration Number: CRD42020171591), and was reported according to the Preferred Reporting Items for Systematic Reviews and Meta-Analyses (PRISMA) 2020 Checklist [23].

\section{Search strategy}

Medline (Pubmed), Embase (Ovid), Web of Science Core Collection, CINAHL Plus (EBSCOhost) and APA PsycINFO (ProQuest) were searched from their inception to March 2021. The search strategy consisted of three parts: (1) "chewing function/ability" or "masticatory function/ ability" or mastication; (2) questionnaire* or subjective" or evaluation" or assessment"; and (3) validation or validity or reliability or psychometric*. The detail search strategies can be found in Additional file 1: Part 1. As a supplement, manual search on the reference lists of published reviews and the included articles, and the Google Scholar was performed.

\section{Eligibility criteria}

Based on the COSMIN guideline, the study inclusion criteria in the present review were: (1) studies investigating the development or validation (measurement properties of interest) of subjective assessment (type of instruments) of masticatory function (construct), regardless of study design; (2) studies on adults (population); and (3) studies published in English with full text available.

The study exclusion criteria were: (1) studies which only included objective assessment of masticatory function; (2) studies that used subjective assessment of masticatory function as an outcome measure only; and (3) case studies, expert opinion, animal studies and reviews.

\section{Study selection and data extraction}

Articles retrieved from the electronic search were imported into the EndNote reference program (Ver. 9.3.1). After removing duplicates, two reviewers (YPF and XS) independently screened the titles and the abstracts of all identified records, and evaluated the full texts of all potentially eligible articles. The following data were extracted from the included articles: first author, year of publication, study participants, study setting, study design, study location, and the characteristics and psychometric properties of PROMs. Any disagreements between the two reviewers were resolved by discussion with an expert researcher (ECML).

\section{Evaluation of the methodological quality of each study}

Methodological quality of the included studies was evaluated using the COSMIN risk of bias checklist [15]. Following the COSMIN manual for systematic reviews of PROMs and the COSMIN methodology for evaluating content validity $[16,18]$, all procedures were conducted by two reviewers (YPF and XS) independently. The COSMIN risk of bias checklist included 10 aspects: PROM development, content validity, structural validity, internal consistency, cross-cultural validity/measurement 
invariance, reliability, measurement error, criterion validity, hypotheses testing for construct validity, and responsiveness. The methodological quality of each aspect was assessed and rated on a 4-point scale: "very good" (V), "adequate" (A), "doubtful" (D), and "inadequate" (I). The ratings were determined based on "the worst score counts" principle, i.e. the lowest rating for any item was the rating for the study [24].

\section{Evaluation of the quality of psychometric properties}

Psychometric properties of the PROM in each included study were rated against the criteria for good measurement properties $[14,25]$. Each property was rated as sufficient $(+)$, insufficient $(-)$ or indeterminate (?). After assessing the quality of the psychometric properties of the PROM in the different studies, the quality of each psychometric property of the PROM was rated as sufficient $(+)$, insufficient $(-)$, inconsistent $( \pm)$ or indeterminate (?). Finally, the level of evidence of each psychometric property of that particular PROM was graded as "high", "moderate", "low" or "very low", using a modified Grading of Recommendations Assessment, Development, and Evaluation (GRADE) approach recommended in the COMSIN guideline [16]. According to the COSMIN guideline, publication bias was not considered when using the modified GRADE to evaluate the measurement properties of PROMs, and only the following four factors were evaluated: risk of bias, inconsistency, imprecision and indirectness.

\section{Results \\ Study selection}

After removal of duplicates, 1850 records were identified (Fig. 1). The titles and abstracts of these records were screened, and 1816 records were excluded. Full texts of 34 articles were assessed and 22 articles were excluded with reasons. Eleven articles were included through the supplementary search (Additional file 1: Part 2). Finally, 23 articles met the inclusion and exclusion criteria.

\section{Characteristics of the included studies and PROMs}

Summary of the 23 included articles reporting on 23 studies and 19 PROMs is presented in Table 1. The total number of participants across all studies was 16,886 and the participants were from all adult age groups. There were 20 cross-sectional studies and three cohort studies. Among these studies, eight were conducted in Japan, four in China, two in Canada, one each in Spain, Iran, Brazil, Croatia, the Republic of Kosovo, Korea, Sudan, Tanzania, and Sweden. The sample size ranged from 20 to 2244. There were four types of PROMs: (1) questions related to chewing specific food items (15 studies, 13 PROMs) [7, 8, 26-38], (2) questions related to chewing problems (three studies, three PROMs)

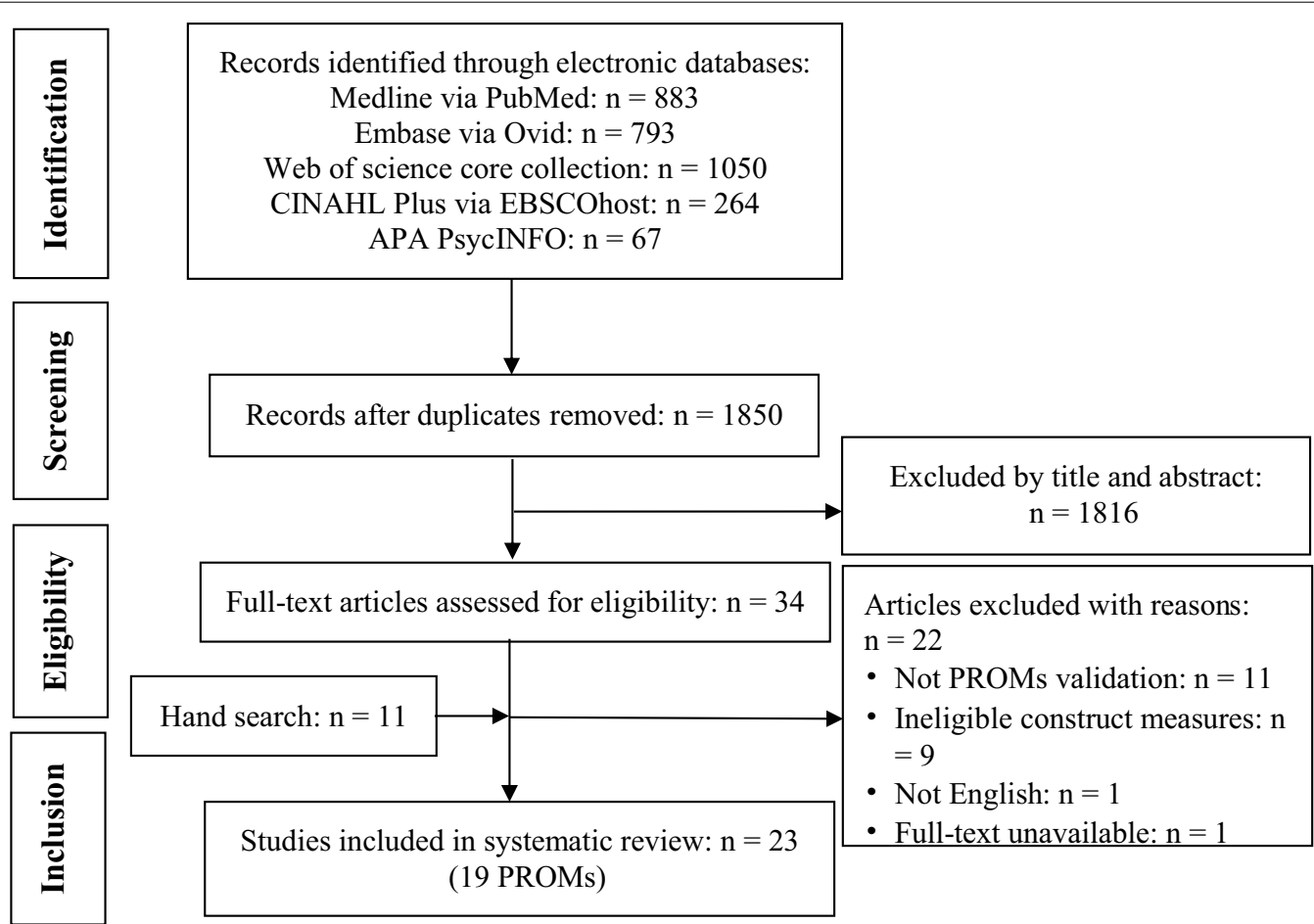

Fig. 1 Flow Diagram, March 2021 


\begin{tabular}{|c|c|c|c|c|c|c|}
\hline 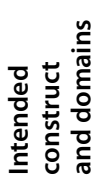 & 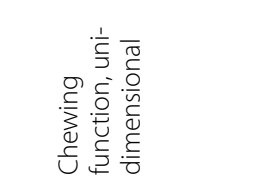 & 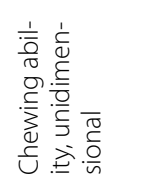 & & 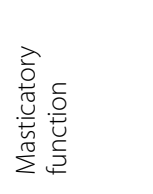 & & 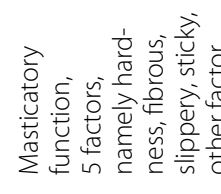 \\
\hline 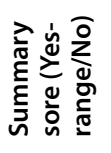 & 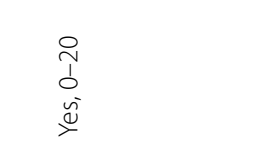 & 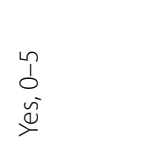 & & 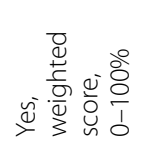 & & 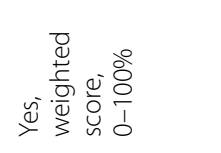 \\
\hline 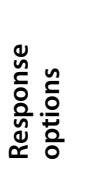 & 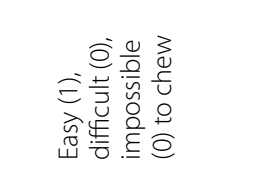 & 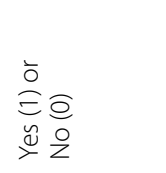 & 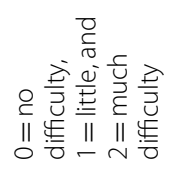 & 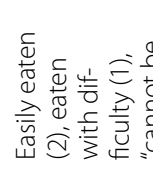 & 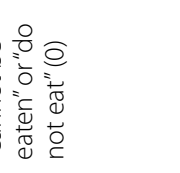 & 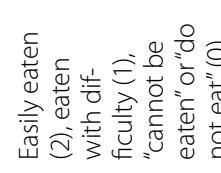 \\
\hline 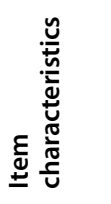 & 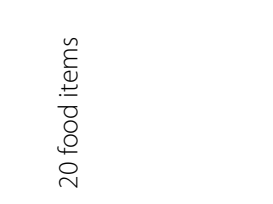 & 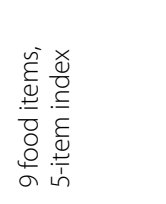 & 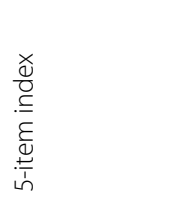 & 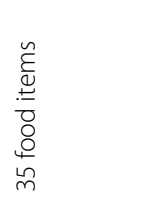 & & 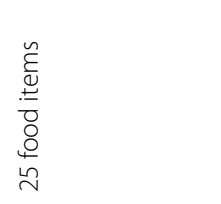 \\
\hline है & $\stackrel{\sim}{\sim}$ & in & & $\stackrel{m}{m}$ & & $\stackrel{\sim}{\sim}$ \\
\hline 离 & 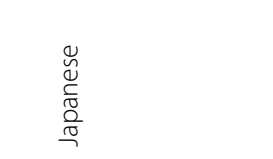 & 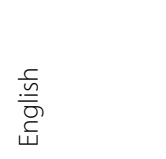 & 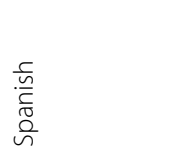 & 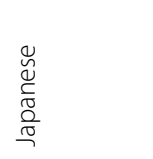 & & 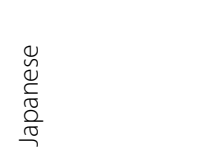 \\
\hline 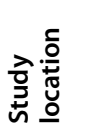 & $\begin{array}{l}\sqrt{0} \\
\text { 0] } \\
\text { I0 }\end{array}$ & $\begin{array}{l}\frac{\pi}{0} \\
\substack{\pi \\
\mathbb{U}}\end{array}$ & $\begin{array}{l}\stackrel{\bar{\pi}}{\overline{0}} \\
\stackrel{0}{n}\end{array}$ & $\begin{array}{l}\frac{\sqrt{0}}{0} \\
\frac{0}{0]}\end{array}$ & & 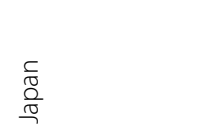 \\
\hline 즐. & 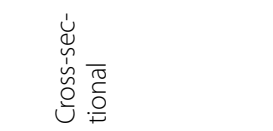 & 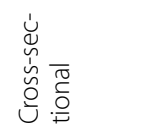 & $\begin{array}{l}\frac{5}{0} \\
\frac{0}{0} \\
\end{array}$ & 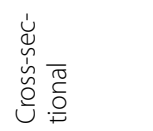 & 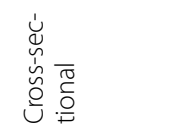 & 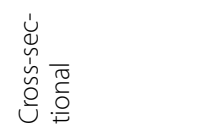 \\
\hline 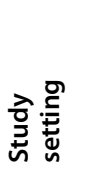 & 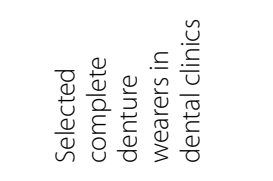 & 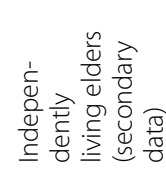 & 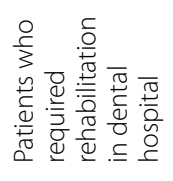 & 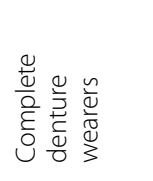 & 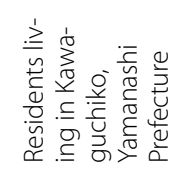 & 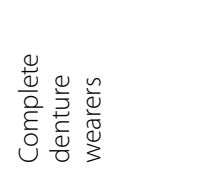 \\
\hline 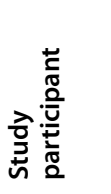 & 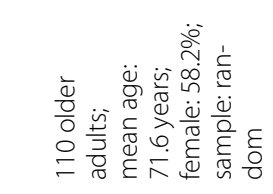 & 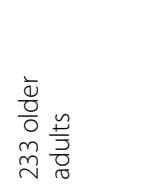 & 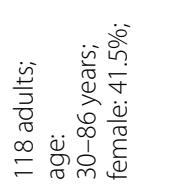 & 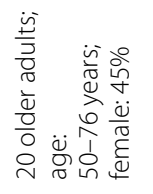 & 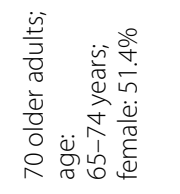 & 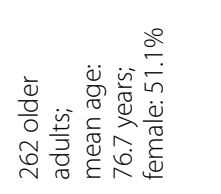 \\
\hline 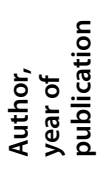 & 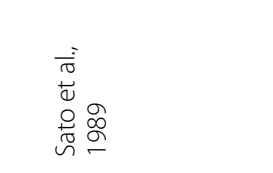 & 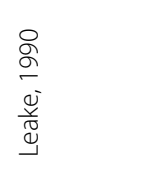 & 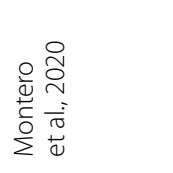 & 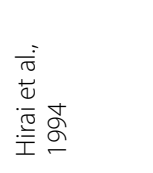 & 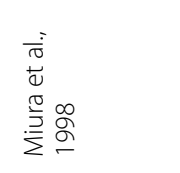 & 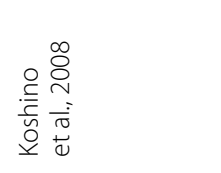 \\
\hline 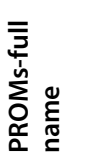 & 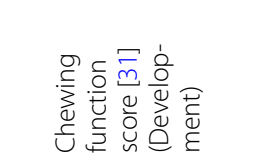 & 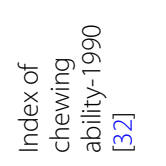 & 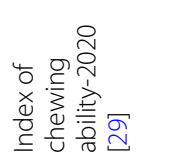 & 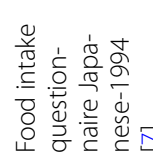 & 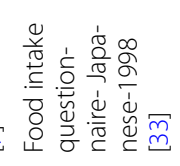 & 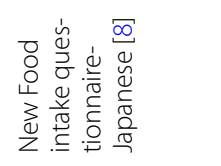 \\
\hline 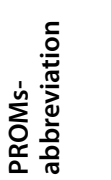 & 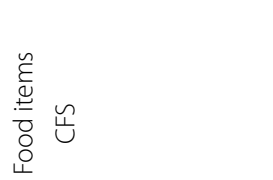 & $\begin{array}{l}8 \\
\text { o } \\
\frac{1}{3} \\
\underline{3}\end{array}$ & $\begin{array}{l}\stackrel{O}{0} \\
\text { ஸे } \\
\underline{1}\end{array}$ & 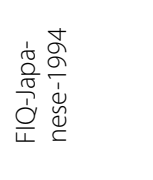 & 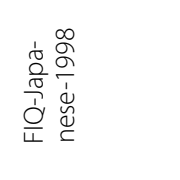 & 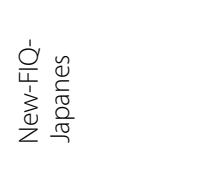 \\
\hline
\end{tabular}




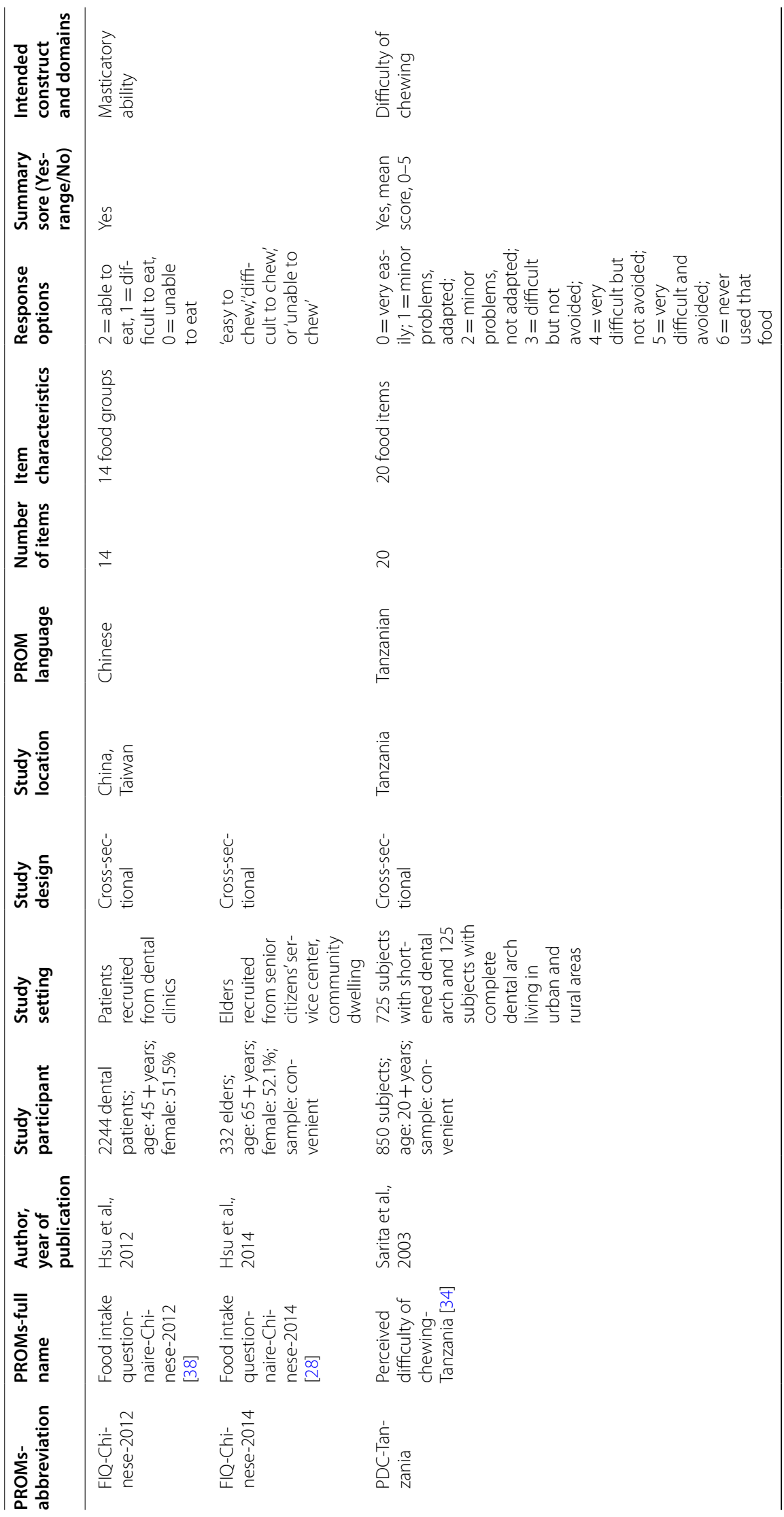




\begin{tabular}{|c|c|c|c|c|}
\hline 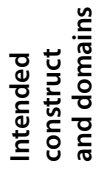 & 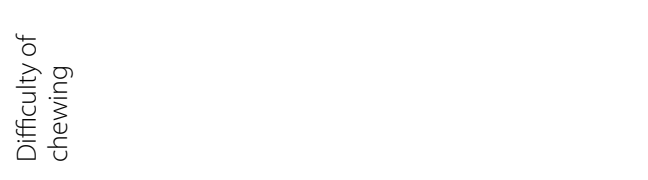 & 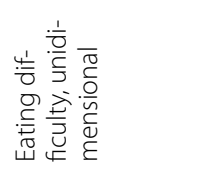 & 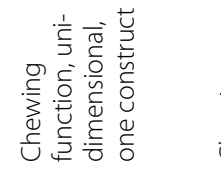 & 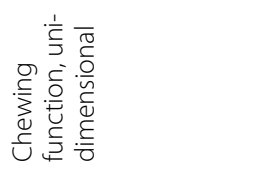 \\
\hline 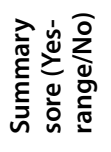 & 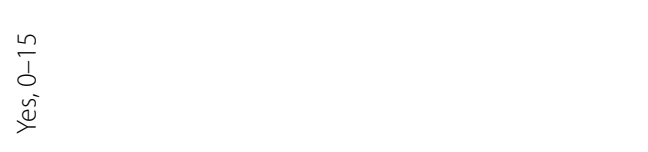 & 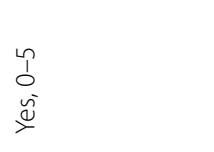 & 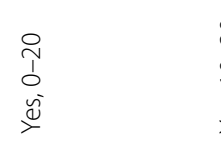 & 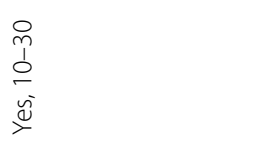 \\
\hline 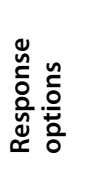 & 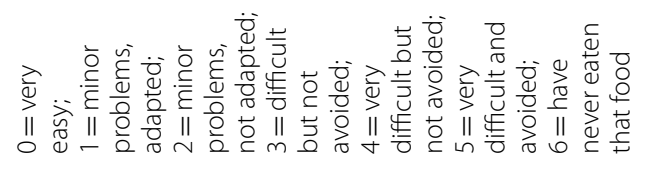 & $\begin{array}{l}\sum_{2} \\
\vdots \\
\stackrel{y}{x}\end{array}$ & 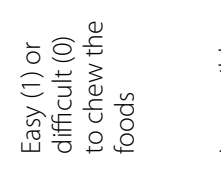 & 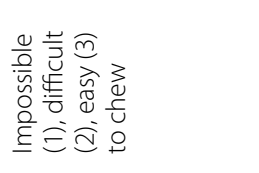 \\
\hline 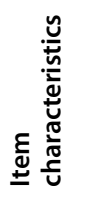 & 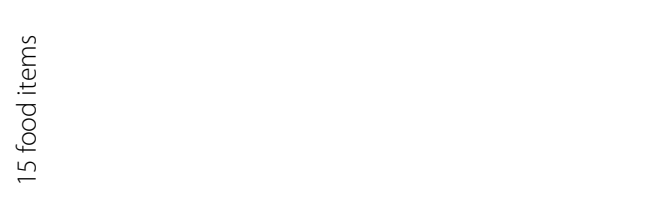 & 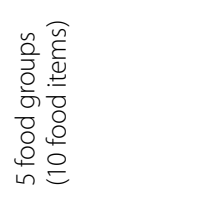 & 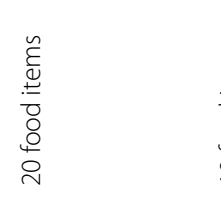 & 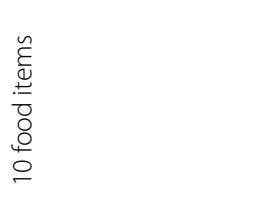 \\
\hline 离 & $\stackrel{n}{\simeq}$ & $\stackrel{\circ}{\circ}$ & . & 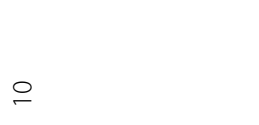 \\
\hline 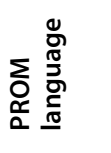 & 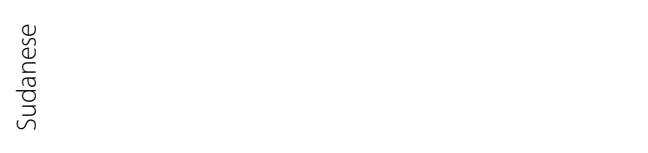 & 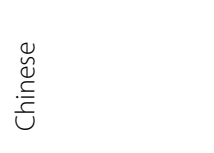 & 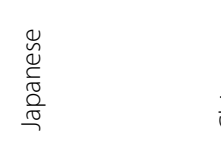 & 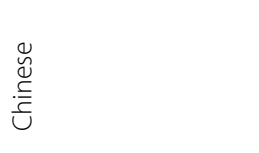 \\
\hline 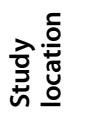 & $\frac{c}{\frac{c}{0}}$ & : & $\begin{array}{l}\frac{1}{0} \\
\frac{0}{0} \\
\frac{0}{n}\end{array}$ & 莺 \\
\hline 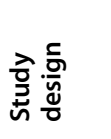 & 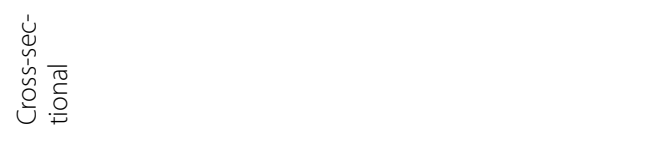 & 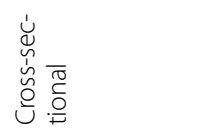 & 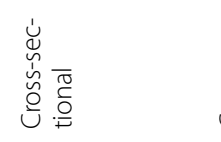 & 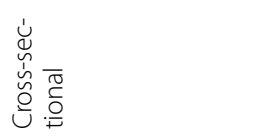 \\
\hline 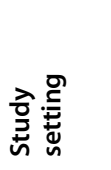 & 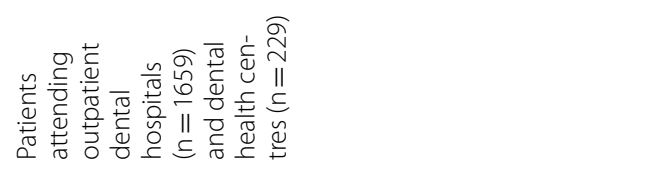 & 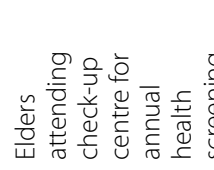 & 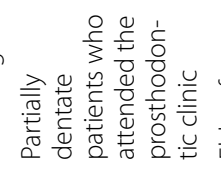 & 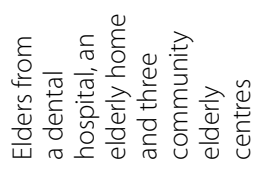 \\
\hline 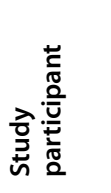 & 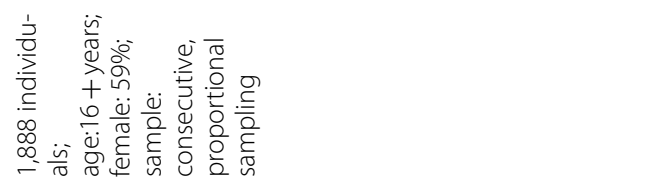 & 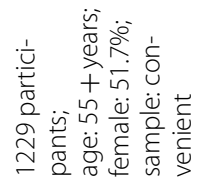 & 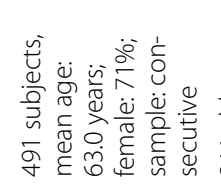 & 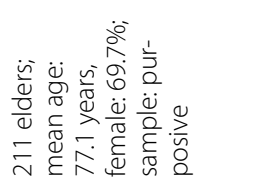 \\
\hline 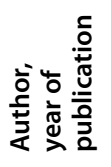 & 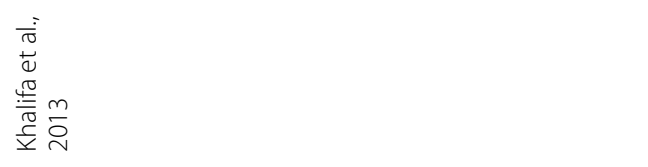 & 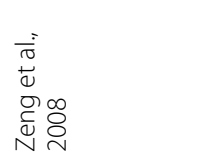 & 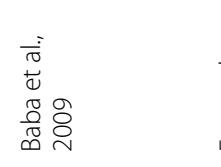 & 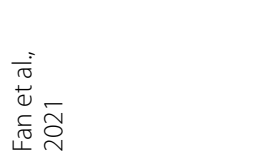 \\
\hline 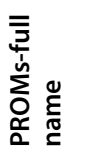 & 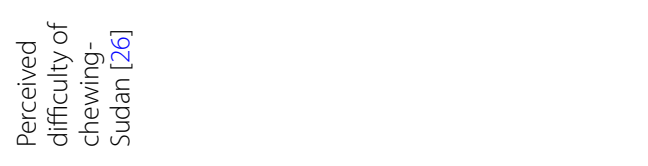 & 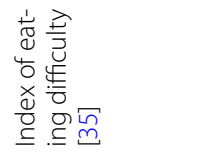 & 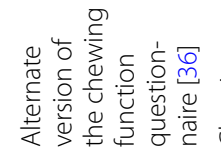 & 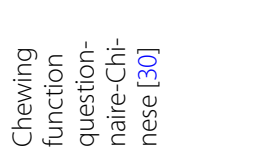 \\
\hline 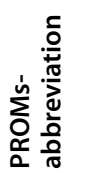 & 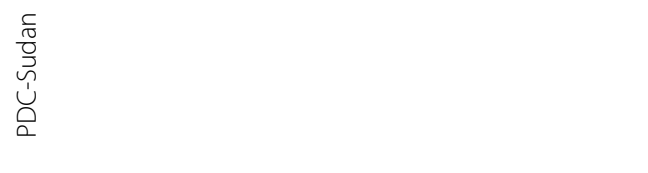 & 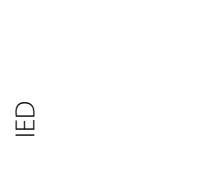 & 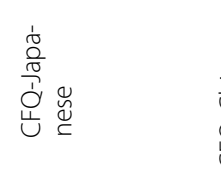 & 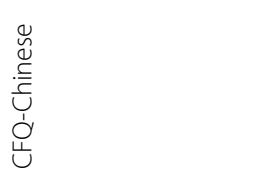 \\
\hline
\end{tabular}




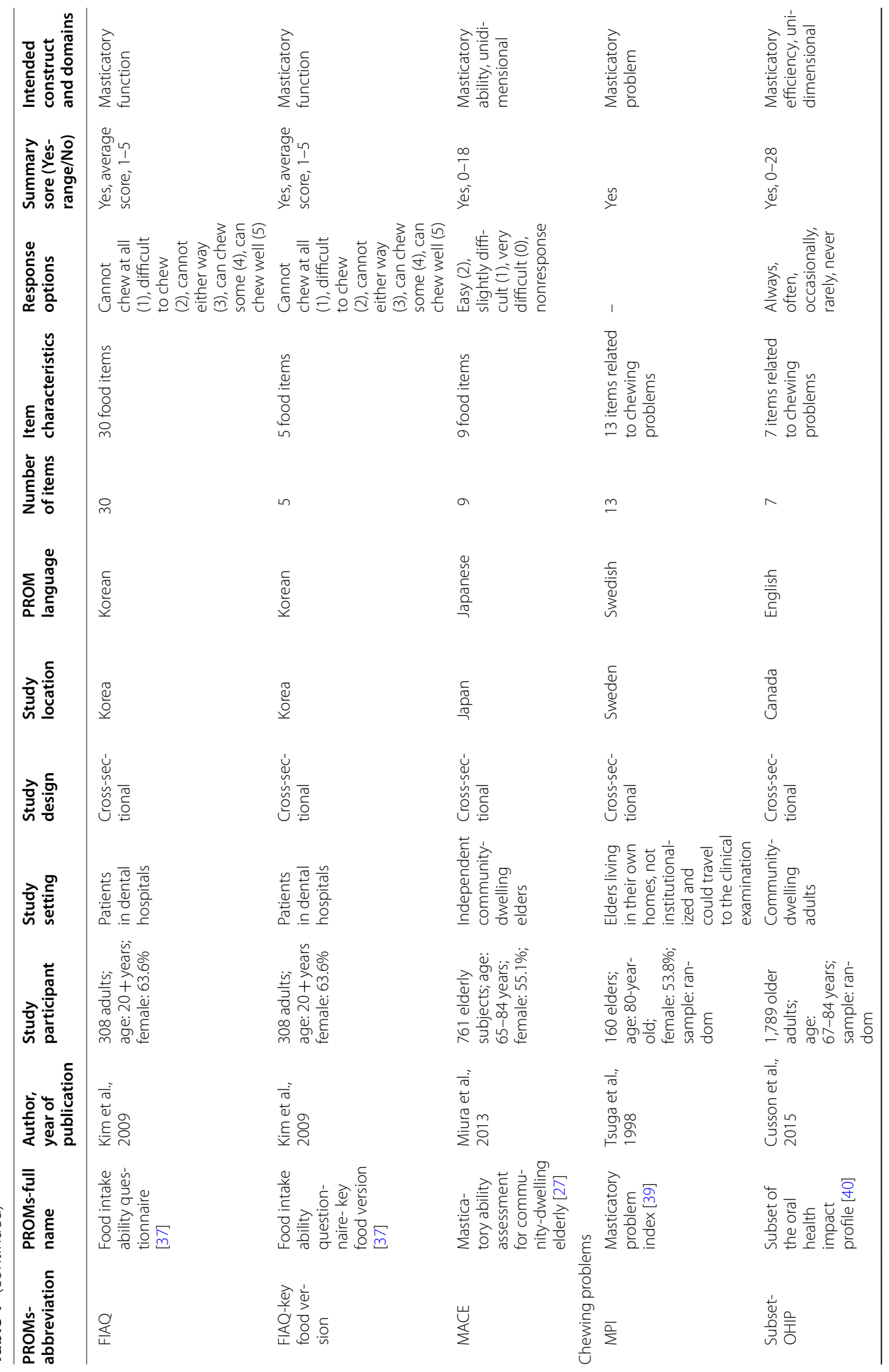




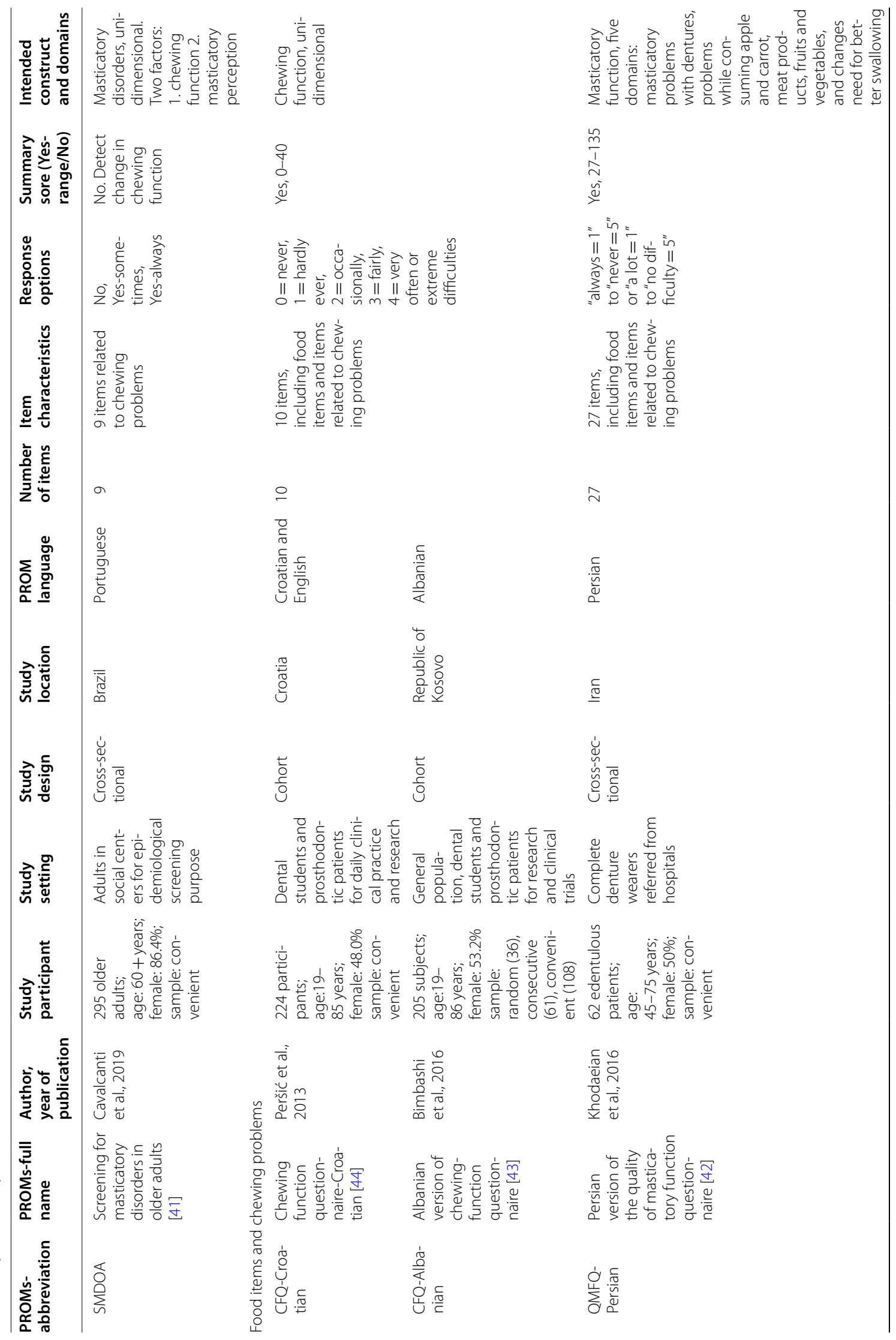




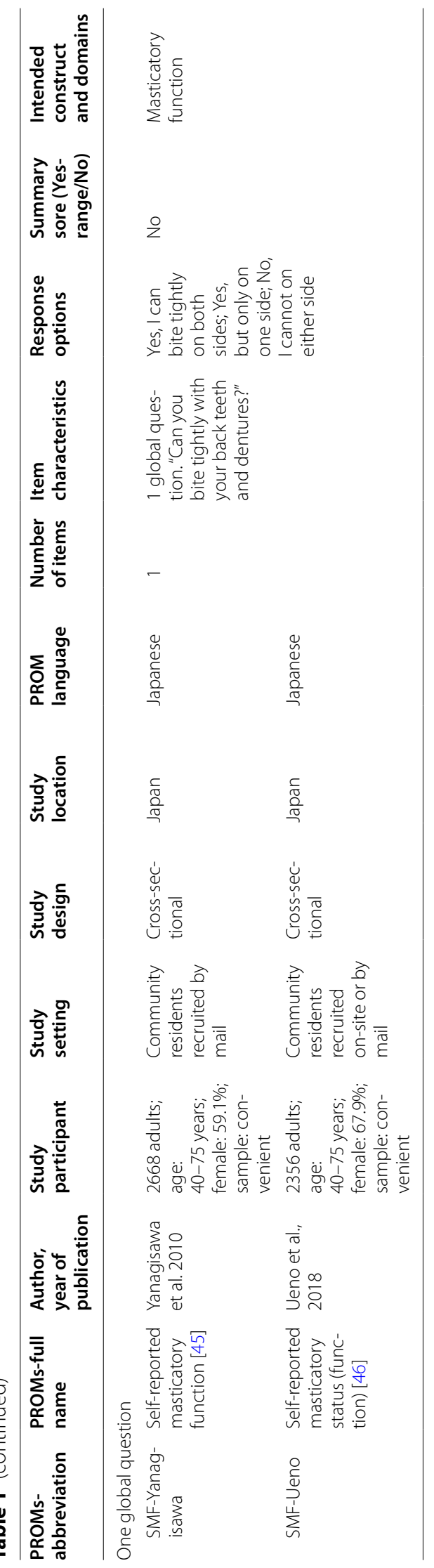


[39-41], (3) questions related to chewing specific food items and questions related to chewing problems (three studies, two PROMs) [42-44], and (4) a global question (two studies, one PROM) [45, 46].

The number of questions in each PROM ranged from seven to 35. Most of the PROMs were unidimensional, except the Persian version of the quality of masticatory function questionnaire (QMFQ-Persian) which contained five domains [42]. Variations were found in the response options of the included PROMs. For the three PROMs with questions about chewing problems, one adopted a five-point Likert-scale ("always", "often", "occasionally", "rarely" and "never") [40], one provided three choices ("No", "Yes-sometimes" and "Yes-always") [41], while the other accepted different responses for different questions [39]. For the PROMs containing questions about chewing specific food items and questions about chewing problems, all adopted a five-point Likert scale response option [42-44]. For the PROM containing only one global question, the response choices were "Yes, I can bite tightly on both sides", "Yes, but only on one side" and "No, I cannot bite on either side" [45, 46]. For the PROMs with questions about chewing specific food items, the response options were based on level of difficulties with slight variations.

\section{Methodological quality of each study}

An overview of the methodological quality assessment of the included studies is presented in Table 2. Nearly all (21 out of 23) studies had conducted hypothesis testing for structural validity and their methodological qualities were rated as adequate or very good. Most of the studies that evaluated internal consistency were rated as doubtful because information on structural validity or unidimensionality of PROMs was not presented [26-28, 32, 34, 35, 38, 40]. For the studies that evaluated structural validity, most studies were rated as adequate or very good, except for the study reporting on QMFQ-Persian, which was rated as inadequate due to insufficient sample size [42]. Of the three studies that evaluated criterion validity, two studies were rated as very good [8, 27], and one was rated as inadequate [37]. Only three studies evaluated responsiveness and their methodological qualities were rated as very good [29, $43,44]$. Regarding cross-cultural validity, two studies were rated as doubtful $[42,43]$. Among the six studies which had evaluated content validity, five were rated as doubtful $[35,41-44]$ while one study was rated as inadequate [30]. Regarding PROM development, six studies described the development process and the methodological qualities of all these studies were rated as doubtful $[30,31,35,38,41,44]$.

\section{Quality of psychometric properties}

Psychometric properties of the PROMs in the individual studies are presented in Table 3. The details can be found in Additional file 1: Part 3. Internal consistency was evaluated in 14 studies, and nine of them were rated as indeterminate, because these studies did not meet the criteria "at least low evidence for sufficient structural validity". Eight studies evaluated test-retest reliability and seven of them were rated as sufficient. Content validity was evaluated in six studies and four of them were rated as sufficient. Eight studies evaluated structural validity and seven of them were rated as sufficient. Only three studies reported criterion validity and two of them were rated as sufficient. Twelve of the 21 studies that had conducted hypothesis testing for construct validity were rated as sufficient. All of the three studies that evaluated responsiveness were rated as sufficient, because the standardized effect size was higher than expected and the results were in accordance with the hypothesis. Two studies performed cross-cultural translation, and both were rated as indeterminate.

\section{Evidence synthesis}

Summarized evidence of the included PROMs is presented in Table 4. The levels of evidence differed amongst the various psychometric properties of the PROMs. Chewing Function Questionnaires-Croatian or Albanian (CFQ-Croatian or Albanian) had a moderate or high level of evidence for internal consistency, test-retest reliability, structural validity, hypothesis testing for construct validity and responsiveness, and these psychometric properties were all rated as sufficient [43, 44]. Food Intake Questionnaire-Japanese (FIQ-Japanese) had moderate level of evidence for sufficient hypothesis testing for construct validity [7, 33]. New Food Intake Questionnaire-Japanese (New-FIQJapanese) had a moderate or high level of evidence for structural validity, criterion validity and hypothesis testing for construct validity, and these psychometric properties were all rated as sufficient [8]. Perceived Difficulty of Chewing-Tanzania (PDC-Tanzania) had moderate level of evidence for sufficient hypothesis testing for construct validity and low level of evidence for indeterminate internal consistency [34]. Chewing Function Questionnaire-Chinese (CFQ-Chinese) had high level of evidence for internal consistency, and moderate level of evidence for test-retest reliability, structural validity and hypothesis testing for construct validity, and these psychometric properties were all rated as sufficient [30]. Screening for Masticatory Disorders in Older Adults (SMDOA) had high level of evidence for structural validity and hypothesis testing for 
Table 2 Methodological quality of the included studies

\begin{tabular}{|c|c|c|c|c|c|c|c|c|c|}
\hline \multirow[t]{2}{*}{ PROMs } & \multirow[t]{2}{*}{$\begin{array}{l}\text { Internal } \\
\text { consistency }\end{array}$} & \multirow{2}{*}{$\begin{array}{l}\text { Test- } \\
\text { retest } \\
\text { reliability }\end{array}$} & \multirow[t]{2}{*}{$\begin{array}{l}\text { Content } \\
\text { validity }\end{array}$} & \multirow[t]{2}{*}{$\begin{array}{l}\text { Structural } \\
\text { validity }\end{array}$} & \multirow[t]{2}{*}{$\begin{array}{l}\text { Criterion } \\
\text { validity }\end{array}$} & \multicolumn{2}{|c|}{$\begin{array}{l}\text { Hypothesis testing for } \\
\text { construct validity }\end{array}$} & \multirow[t]{2}{*}{ Responsiveness } & \multirow{2}{*}{$\begin{array}{l}\text { Cross-cultural } \\
\text { translation/ } \\
\text { validity }\end{array}$} \\
\hline & & & & & & $\begin{array}{l}\text { Convergent } \\
\text { validity }\end{array}$ & $\begin{array}{l}\text { Discriminative } \\
\text { validity }\end{array}$ & & \\
\hline \multicolumn{10}{|l|}{ Food items } \\
\hline CFS [31] & 0 & 0 & 0 & 0 & 0 & 0 & 0 & 0 & 0 \\
\hline ICA-1990 [32] & $\mathrm{D}$ & 0 & 0 & 0 & 0 & A & 0 & 0 & 0 \\
\hline ICA-2020 [29] & 0 & 0 & 0 & 0 & 0 & 0 & 0 & V & 0 \\
\hline $\begin{array}{l}\text { FIQ-Japa- } \\
\text { nese-1994 } \\
{[7]}\end{array}$ & 0 & 0 & 0 & 0 & 0 & V & 0 & 0 & 0 \\
\hline $\begin{array}{l}\text { FIQ-Japa- } \\
\text { nese-1998 } \\
{[33]}\end{array}$ & 0 & 0 & 0 & 0 & 0 & A & 0 & 0 & 0 \\
\hline $\begin{array}{l}\text { New-FIQ- } \\
\text { Japanese [8] }\end{array}$ & $\mathrm{D}$ & 0 & 0 & A & V & V & 0 & 0 & 0 \\
\hline $\begin{array}{l}\text { FIQ-Chi- } \\
\text { nese-2012 } \\
{[38]}\end{array}$ & $\mathrm{D}$ & $\mathrm{D}$ & 0 & 0 & 0 & 0 & V & 0 & 0 \\
\hline $\begin{array}{l}\text { FlQ-Chi- } \\
\text { nese-2014 } \\
{[28]}\end{array}$ & D & $\mathrm{D}$ & 0 & 0 & 0 & 0 & A & 0 & 0 \\
\hline $\begin{array}{l}\text { PDC-Tanza- } \\
\text { nia [34] }\end{array}$ & D & 0 & 0 & 0 & 0 & 0 & A & 0 & 0 \\
\hline $\begin{array}{l}\text { PDC-Sudan } \\
{[26]}\end{array}$ & $\mathrm{D}$ & A & 0 & 0 & 0 & A & 0 & 0 & 0 \\
\hline IED [35] & $\mathrm{D}$ & D & $\mathrm{D}$ & 0 & 0 & A & 0 & 0 & 0 \\
\hline $\begin{array}{l}\text { CFQ-Japa- } \\
\text { nese [36] }\end{array}$ & V & A & 0 & A & 0 & A & 0 & 0 & 0 \\
\hline $\begin{array}{l}\text { CFQ-Chinese } \\
{[30]}\end{array}$ & V & A & I & A & 0 & A & A & 0 & 0 \\
\hline FIAQ [37] & 0 & 0 & 0 & A & 0 & A & A & 0 & 0 \\
\hline $\begin{array}{l}\text { FIAQ-key } \\
\text { food [37] }\end{array}$ & 0 & 0 & 0 & 0 & I & A & A & 0 & 0 \\
\hline MACE [27] & $\mathrm{D}$ & 0 & 0 & 0 & V & A & 0 & 0 & 0 \\
\hline \multicolumn{10}{|c|}{ Chewing problems } \\
\hline MPI [39] & 0 & 0 & 0 & 0 & 0 & A & 0 & 0 & 0 \\
\hline $\begin{array}{l}\text { Subset-OHIP } \\
{[40]}\end{array}$ & $\mathrm{D}$ & 0 & 0 & 0 & 0 & V & 0 & 0 & 0 \\
\hline SMDOA [41] & 0 & 0 & $\mathrm{D}$ & V & 0 & 0 & V & 0 & 0 \\
\hline \multicolumn{10}{|c|}{ Food items and chewing problems } \\
\hline $\begin{array}{l}\text { CFQ-Croa- } \\
\operatorname{tian}[44]\end{array}$ & V & V & $\mathrm{D}$ & A & 0 & A & V & V & 0 \\
\hline $\begin{array}{l}\text { CFQ-Alba- } \\
\text { nian [43] }\end{array}$ & V & V & $\mathrm{D}$ & A & 0 & A & V & V & $\mathrm{D}$ \\
\hline $\begin{array}{l}\text { QMFQ-Per- } \\
\text { sian [42] }\end{array}$ & V & 0 & D & । & 0 & A & 0 & 0 & $\mathrm{D}$ \\
\hline \multicolumn{10}{|c|}{ One global question } \\
\hline $\begin{array}{l}\text { SMF-Yanagi- } \\
\text { sawa [45] }\end{array}$ & 0 & 0 & 0 & 0 & 0 & A & 0 & 0 & 0 \\
\hline $\begin{array}{l}\text { SMF-Ueno } \\
{[46]}\end{array}$ & 0 & 0 & 0 & 0 & 0 & A & 0 & 0 & 0 \\
\hline
\end{tabular}

$V$, very good; $A$, adequate; $D$, doubtful; 1 , inadequate; 0 , no data available 
Table 3 Psychometric properties of the included PROMs

\begin{tabular}{|c|c|c|c|c|c|c|c|c|}
\hline PROMs & $\begin{array}{l}\text { Internal } \\
\text { consistency }\end{array}$ & $\begin{array}{l}\text { Test-retest } \\
\text { reliability }\end{array}$ & $\begin{array}{l}\text { Content } \\
\text { validity }\end{array}$ & $\begin{array}{l}\text { Structural } \\
\text { validity }\end{array}$ & $\begin{array}{l}\text { Criterion } \\
\text { validity }\end{array}$ & $\begin{array}{l}\text { Hypothesis testing } \\
\text { for construct } \\
\text { validity }\end{array}$ & Responsiveness & $\begin{array}{l}\text { Cross-cultural } \\
\text { translation/ } \\
\text { validity }\end{array}$ \\
\hline \multicolumn{9}{|l|}{ Food items } \\
\hline CFS [31] & 0 & 0 & 0 & 0 & 0 & 0 & 0 & 0 \\
\hline ICA-1990 [32] & $?$ & 0 & 0 & 0 & 0 & $?$ & 0 & 0 \\
\hline ICA-2020 [29] & 0 & 0 & 0 & 0 & 0 & 0 & + & 0 \\
\hline FIQ-Japanese-1994 [7] & 0 & 0 & 0 & 0 & 0 & + & 0 & 0 \\
\hline $\begin{array}{l}\text { FlQ-Japanese-1998 } \\
\text { [33] }\end{array}$ & 0 & 0 & 0 & 0 & 0 & + & 0 & 0 \\
\hline New-FIQ-Japanese [8] & $?$ & 0 & 0 & + & + & + & 0 & 0 \\
\hline FIQ-Chinese-2012 [38] & $?$ & + & 0 & 0 & 0 & + & 0 & 0 \\
\hline FIQ-Chinese-2014 [28] & $?$ & + & 0 & 0 & 0 & - & 0 & 0 \\
\hline PDC-Tanzania [34] & $?$ & 0 & 0 & 0 & 0 & + & 0 & 0 \\
\hline PDC-Sudan [26] & $?$ & + & 0 & 0 & 0 & $?$ & 0 & 0 \\
\hline IED [35] & $?$ & + & $?$ & 0 & 0 & - & 0 & 0 \\
\hline CFQ-Japanese [36] & + & - & 0 & + & 0 & - & 0 & 0 \\
\hline CFQ-Chinese [30] & + & + & $?$ & + & 0 & + & 0 & 0 \\
\hline FIAQ [37] & 0 & 0 & 0 & $?$ & 0 & - & 0 & 0 \\
\hline FIAQ-key food [37] & 0 & 0 & 0 & 0 & $?$ & + & 0 & 0 \\
\hline MACE [27] & $?$ & 0 & 0 & 0 & + & - & 0 & 0 \\
\hline \multicolumn{9}{|l|}{ Chewing problems } \\
\hline MPI [39] & 0 & 0 & 0 & 0 & 0 & - & 0 & 0 \\
\hline Subset-OHIP [40] & $?$ & 0 & 0 & 0 & 0 & - & 0 & 0 \\
\hline SMDOA [41] & 0 & 0 & + & + & 0 & + & 0 & 0 \\
\hline \multicolumn{9}{|c|}{ Food items and chewing problems } \\
\hline CFQ-Croatian [44] & + & + & $+?$ & + & 0 & + & + & 0 \\
\hline CFQ-Albanian [43] & + & + & $+?$ & + & 0 & + & + & $?$ \\
\hline QMFQ-Persian [42] & + & 0 & + & + & 0 & - & 0 & $?$ \\
\hline \multicolumn{9}{|l|}{ One global question } \\
\hline SMF-Yanagisawa [45] & 0 & 0 & 0 & 0 & 0 & + & 0 & 0 \\
\hline SMF-Ueno [46] & 0 & 0 & 0 & 0 & 0 & + & 0 & 0 \\
\hline
\end{tabular}

The hypothesis for evaluating convergent validity was if a correlation between the PROM under study and the comparator instrument measuring the similar construct was $\geq 0.50$, it was considered as sufficient [60]. The hypothesis testing for evaluating discriminant validity and responsiveness were in accordance with that in individual studies

$+=$ sufficient $;-=$ insufficient; $?=$ indeterminate; $0=$ no data available

construct validity, and low level of evidence for content validity, and these psychometric properties were all rated as sufficient [41].

\section{Discussion}

This review yielded two major findings: (1) although 19 PROMs for masticatory function were identified, none of them had high-level evidence for all of the sufficient psychometric properties; and (2) CFQ (Croatian or Albanian), FIQ-Japanese, new-FIQ-Japanese, CFQ-Chinese, SMDOA and PDC-Tanzania have better psychometric properties than the other PROMs.

\section{Comparison with previous reviews}

There is a recent consensus report on the assessment of masticatory function [5] in the literature. In the consensus report [5], five PROMs for masticatory function were mentioned, among which four were included in the present review. The PROM that was not included in the present review was an instrument containing three questions based on the international classification of functioning, disability and health (ICF) model for oral function [47]. The reason for not including this PROM is the development or validation of the PROM was not reported in the literature. 
Table 4 Evidence synthesis of the included PROMs

\begin{tabular}{|c|c|c|c|c|c|c|c|c|}
\hline PROMs & $\begin{array}{l}\text { Internal } \\
\text { consistency }\end{array}$ & $\begin{array}{l}\text { Test-retest } \\
\text { reliability }\end{array}$ & $\begin{array}{l}\text { Content } \\
\text { validity }\end{array}$ & $\begin{array}{l}\text { Structural } \\
\text { validity }\end{array}$ & $\begin{array}{l}\text { Criterion } \\
\text { validity }\end{array}$ & $\begin{array}{l}\text { Hypothesis } \\
\text { testing for } \\
\text { construct } \\
\text { validity }\end{array}$ & Responsiveness & $\begin{array}{l}\text { Cross-cultural } \\
\text { translation/ } \\
\text { validity }\end{array}$ \\
\hline \multicolumn{9}{|l|}{ Food items } \\
\hline CFS [31] & 0 & 0 & 0 & 0 & 0 & 0 & 0 & 0 \\
\hline \multicolumn{9}{|c|}{ Level of evidence } \\
\hline ICA $[29,32]$ & $?$ & 0 & 0 & 0 & 0 & $?$ & + & 0 \\
\hline Level of evidence & Low & & & & & Moderate & High & \\
\hline $\begin{array}{l}\text { FIQ-Japanese } \\
{[7,33]}\end{array}$ & 0 & 0 & 0 & 0 & 0 & + & 0 & 0 \\
\hline Level of evidence & & & & & & Moderate & & \\
\hline $\begin{array}{l}\text { New-FIQ-Japa- } \\
\text { nese [8] }\end{array}$ & $?$ & 0 & 0 & + & + & + & 0 & 0 \\
\hline Level of evidence & Low & & & Moderate & High & High & & \\
\hline $\begin{array}{l}\text { FIQ-Chinese [28, } \\
\text { 38] }\end{array}$ & $?$ & + & 0 & 0 & 0 & \pm & 0 & 0 \\
\hline Level of evidence & Moderate & \multicolumn{4}{|l|}{ Moderate } & \multicolumn{3}{|l|}{ Moderate } \\
\hline $\begin{array}{l}\text { PDC-Tanzania } \\
{[34]}\end{array}$ & $?$ & 0 & 0 & 0 & 0 & + & 0 & 0 \\
\hline Level of evidence & Low & & & & & Moderate & & \\
\hline PDC-Sudan [26] & $?$ & + & 0 & 0 & 0 & $?$ & 0 & 0 \\
\hline Level of evidence & Low & \multicolumn{4}{|l|}{ Moderate } & \multicolumn{3}{|l|}{ Moderate } \\
\hline IED [35] & $?$ & + & $?$ & 0 & 0 & - & 0 & 0 \\
\hline Level of evidence & Low & Low & Low & & & Moderate & & \\
\hline $\begin{array}{l}\text { CFQ-Japanese } \\
\text { [36] }\end{array}$ & + & - & 0 & + & 0 & - & 0 & 0 \\
\hline Level of evidence & Moderate & \multicolumn{2}{|l|}{ Moderate } & \multicolumn{2}{|l|}{ Moderate } & \multicolumn{3}{|l|}{ Moderate } \\
\hline CFQ-Chinese [30] & + & + & $?$ & + & 0 & + & 0 & 0 \\
\hline Level of evidence & Moderate & Moderate & Very low & Moderate & & Moderate & & \\
\hline FIAQ [37] & 0 & 0 & 0 & $?$ & 0 & - & 0 & 0 \\
\hline \multicolumn{4}{|l|}{ Level of evidence } & \multicolumn{2}{|l|}{ Moderate } & \multicolumn{3}{|l|}{ Moderate } \\
\hline $\begin{array}{l}\text { FIAQ-key food } \\
{[37]}\end{array}$ & 0 & 0 & 0 & 0 & $?$ & + & 0 & 0 \\
\hline Level of evidence & & & & & Very low & Moderate & & \\
\hline MACE [27] & $?$ & 0 & 0 & 0 & + & - & 0 & 0 \\
\hline Level of evidence & Low & & & & High & Moderate & & \\
\hline \multicolumn{9}{|c|}{ Chewing problems } \\
\hline MPI [39] & 0 & 0 & 0 & 0 & 0 & - & 0 & 0 \\
\hline Level of evidence & & & & & & Moderate & & \\
\hline Subset-OHIP [40] & + & 0 & 0 & 0 & 0 & - & 0 & 0 \\
\hline Level of evidence & High & & & & & High & & \\
\hline SMDOA [41] & 0 & 0 & + & + & 0 & + & 0 & 0 \\
\hline Level of evidence & & & Low & High & & High & & \\
\hline \multicolumn{9}{|c|}{ Food items and chewing problems } \\
\hline $\begin{array}{l}\text { CFQ (Croatian, } \\
\text { Albanian) }[43,44]\end{array}$ & + & + & $+?$ & + & 0 & + & + & $?$ \\
\hline Level of evidence & High & High & Moderate & Moderate & & Moderate & High & Low \\
\hline $\begin{array}{l}\text { QMFQ-Persian } \\
\text { [42] }\end{array}$ & + & 0 & + & + & 0 & - & 0 & $?$ \\
\hline Level of evidence & Very low & & Low & Very low & & High & & Very low \\
\hline
\end{tabular}


Table 4 (continued)

\begin{tabular}{|c|c|c|c|c|c|c|c|c|}
\hline PROMs & $\begin{array}{l}\text { Internal } \\
\text { consistency }\end{array}$ & $\begin{array}{l}\text { Test-retest } \\
\text { reliability }\end{array}$ & $\begin{array}{l}\text { Content } \\
\text { validity }\end{array}$ & $\begin{array}{l}\text { Structural } \\
\text { validity }\end{array}$ & $\begin{array}{l}\text { Criterion } \\
\text { validity }\end{array}$ & $\begin{array}{l}\text { Hypothesis } \\
\text { testing for } \\
\text { construct } \\
\text { validity }\end{array}$ & Responsiveness & $\begin{array}{l}\text { Cross-cultural } \\
\text { translation/ } \\
\text { validity }\end{array}$ \\
\hline \multicolumn{9}{|l|}{ One global question } \\
\hline $\operatorname{SMF}[45,46]$ & 0 & 0 & 0 & 0 & 0 & + & 0 & 0 \\
\hline Level of evidence & & & & & & High & & \\
\hline
\end{tabular}

$+=$ sufficient; $-=$ insufficient $;=$ inconsistent; $?=$ indeterminate; $0=$ no data available

In a recent systematic review of PROMs for adult dental patients [19], only two out the 20 questionnaires were on masticatory function and they were included in the present review. There were three other questionnaires included in that systematic review but they were not included in the present review because they focused on jaw function and not masticatory function.

Since the methodological quality and psychometric properties of PROMs for masticatory function have not been reported in previous systematic reviews, no comparison regarding the findings from the present review and those of earlier reviews can be made.

\section{Recommendations on methodology and psychometric property for future research}

In the present review, only six studies described the PROM development process and this was only briefly presented [30, 31, 35, 38, 41, 44]. It is hard to tell whether the PROM development process had not been properly carried out or was just not reported. Detailed information about the PROMs development process should be described in future research.

None of the 23 studies included in the present review tested the measurement errors. Measurement error is defined as "the systematic and random error of a study participant's score that is not attributed to true changes in the construct to be measured" [48]. The measurement error will be rated as sufficient if the minimal important change (MIC) is larger than the smallest detectable change (SDC), or MIC is outside the limits of agreement (LOA). A PROM can be used to compare masticatory function of different people or the same person at different time points. The difference between two scores may originate from the measurement error or the real difference/change. Lack of assessment of the measurement error may affect judgment. Thus, the measurement error of PROMs should be evaluated in future studies in order to obtain accurate results and to draw valid conclusions.

The present review found that only two studies evaluated the cross-cultural validity of the PROMs but they only conducted forward-backward translation [42, 43]. It is not sufficient for the evaluation of cross-cultural validity by merely performing forward-backward translation or by conducting a pilot study on a sample with a different culture without carrying out proper statistical analysis. To assess cross-cultural validity of PROMs in future studies, regression analyses or confirmatory factor analysis (CFA) using classical test theory (CTT) methods, and differential item functioning (DIF) analyses using item response theory (IRT) methods are recommended [49-52].

Responsiveness is defined as "the ability to detect clinically important change" or as "the ability to detect a change in the construct to be measured" [48]. In the present review, there were only three longitudinal studies, two on CFQ (Croatian or Albanian) and one study on the Index of Chewing Ability (ICA, 2020), which evaluated the responsiveness of the PROMs through the change scores collected before and after prosthodontic treatment $[29,43,44]$. The responsiveness of the other 17 PROMs was not studied and they may not be able to detect changes in masticatory function. Therefore, further studies should be conducted to evaluate the responsiveness of PROMs. In addition, the time span needed to capture the score difference in different populations, e.g. young adults and older adults, should be taken into consideration when designing such studies. The effect sizes (mean change score/SD baseline) [53], standardized response mean (mean change score/SD change score) [54], Norman's responsiveness coefficient ( $\sigma^{2}$ change/ $\sigma^{2}$ change $+\sigma^{2}$ error) [55], and relative efficacy statistics $\left(\left(\mathrm{t} \text {-statistic }{ }_{1} / \mathrm{t} \text {-statistic }{ }_{2}\right)^{2}\right)$ [56] are appropriate statistical methods to evaluate responsiveness. In contrast, use of paired $t$-test is not appropriate for this purpose [57].

Content validity was only evaluated in five of the 19 PROMs included in the present review, and none of these PROMs have high level of evidence on content validity. It is worth emphasizing that content validity, defined as the degree to which the content of a PROM is an adequate reflection of the construct to be measured [48], is widely regarded as the most important type of validity for PROMs [58]. Asking study participants about the relevance, comprehensiveness and comprehensibility of 
a PROM, and obtaining the views of professionals about the relevance and comprehensiveness of a PROM, are essential when designing a PROM with sufficient content validity and strong level of evidence [58]. It is strongly recommended that future research can refer to the COSMIN guideline to develop all PROMs that have sufficient validity with strong level of evidence.

\section{Recommendations on the selection of appropriate PROMs for future research}

The PROMs included in this review were put into three categories based on the COSMIN manual [16]. Category A includes PROMs with evidence for sufficient content validity (any level) and at least low quality evidence for sufficient internal consistency. Category $\mathrm{C}$ includes PROMs with high quality evidence for an insufficient measurement property. PROMs which cannot be categorized as either $\mathrm{A}$ or $\mathrm{C}$ are put into category $\mathrm{B}$. The PROMs categorized as "A" are recommended for use while those categorized as " $\mathrm{C}$ " are not recommended. PROMs categorized as " $\mathrm{B}$ " have potentials to be recommended, but further studies are needed to assess their qualities [16].

Results of the present review show that CFQ (Croatian or Albanian) [43, 44] can meet the inclusion criteria of category A, while Subset of the Oral Health Impact Profile (Subset-OHIP) [40] and QMFQ [42] are in category $\mathrm{C}$. The other PROMs are categorized into B. Thus, only CFQ (Croatian or Albanian) is recommended for use. The PROMs in category $\mathrm{B}$ can be further divided into two sub-categories according to the rating of hypothesis testing for construct validity. Hypothesis testing for construct validity refers to the extent of subjective assessment related to other measures that are consistent with theoretical measurement construct $[25,59]$. If the hypothesis testing of a PROM is rated as sufficient, it can be re-classified into category B1 and has the potential to be recommended for use. Otherwise, if the hypothesis testing of a PROM is rated as insufficient or indeterminate, it will be categorized into B2 and will need further research to assess its quality. Results of the present review show that FIQ-Japanese [7, 33], new-FIQ-Japanese [8], PDCTanzania [34], CFQ-Chinese [30], and SMDOA [41] can be classified into category B1, while ICA-1990 [32], PDC-Sudan [26], Index of Eating Difficulty (IED) [35], CFQ-Japanese [36], Food Intake Ability Questionnaire (FIAQ) [37], Masticatory Ability assessment for the Community-dwelling Elderly (MACE) [27] and Masticatory Problem Index (MPI) [39] are in the category B2. Although, Food Intake Ability Questionnaire-key food version (FIAQ-key food version) [37] and Selfreported Masticatory Function (SMF) $[45,46]$ may be classified as B1, these two PROMs need more research to fully assess their quality. It is difficult to classify FIQChinese $[28,38]$ into B1 or B2 because the convergent validity was rated as insufficient though its discriminative validity was rated as sufficient. Further studies on this PROM are needed.

In addition to the above-mentioned measurement properties, feasibility and interpretability of PROMs should also be considered when making recommendations for use [17]. Feasibility refers to the ease of PROM application, such as completion time and cost, while interpretability refers to the relationship between PROM scores and clinical meaning [48]. Considering all the evaluated properties of the PROMs included in the present review, CFQ (Croatian or Albanian) is recommended for use, and FIQ-Japanese, new-FIQ-Japanese, PDC-Tanzania, CFQ-Chinese and SMDOA have the potential to be recommended for use.

Based on the results of this systematic review, none of the included PROMs can be considered as the "gold standard". Nevertheless, some PROMs have better psychometric properties than others, and may be suitable for certain populations. Specially, CFQ (Croatian or Albanian) is recommended to be used to assess masticatory function of general prosthodontic patients. FIQJapanese and New-FIQ-Japanese may be recommended to assess masticatory function of complete denture wearers. SMDOA, CFQ-Chinese and PDC-Tanzania may be recommended to assess masticatory function of community-dwelling adults in epidemiological screening.

To the best of our knowledge, this is the first systematic review on PROMs for masticatory function based on the COSMIN guideline. In addition, this review provides recommendations for the selection of appropriate PROMs for masticatory function. Moreover, this review points out the commonly neglected methodological aspects among the included studies and provides suggestions for future research. Regarding the limitations of the present review, only articles published in English were included and this may result in omission of potentially excellent PROMs reported in articles published in non-English languages. Besides, the PROM development or validation processes may have been rigorously implemented in some studies but were not reported in detail, which may lead to a downgrade of their methodological quality ratings. It is strongly recommended that future studies refer to the COSMIN guideline when developing or validating PROMs.

\section{Conclusions}

Currently, there is no PROM for masticatory function in adults with high-level evidence on all the psychometric properties. There are variations in the psychometric 
properties among the different reported PROMs. Within the limitations and current evidence of this systematic review, CFQ (Croatian or Albanian), FIQ-Japanese, new-FIQ-Japanese, CFQ-Chinese, SMDOA and PDCTanzania outperform other measurement tools. However, well-designed studies on PROMs are needed in the future.

\section{Abbreviations}

PROMs: Patient-Reported Outcome Measures; COSMIN: COnsensus-based Standards for the selection of health Measurement INstruments.

\section{Supplementary Information}

The online version contains supplementary material available at https://doi. org/10.1186/s12903-021-01949-7.

Additional file 1: Search strategy, articles from the supplementary search, and details about reliability and validity assessments of the included PROMs.

\section{Acknowledgements}

Not applicable.

\section{Authors' contributions}

ECML, YF and XS contributed to the design of the work; YF and XS contributed to the data extraction, analysis and interpretation; YPF drafted the paper; XS, KCML and ECML revised the paper critically. All authors read and approved the final manuscript.

\section{Funding}

This work was supported by the Tam Wah Ching Endowed Professorship, University of Hong Kong. The funding source was not involved in the design of the review and data collection, analysis, and interpretation of data and in writing or submission of the manuscript for publication.

\section{Availability of data and materials}

All data generated and analyzed in this review are included in the articles.

\section{Declarations}

Ethics approval and consent to participate

Not applicable.

\section{Consent for publication}

Not applicable.

\section{Competing interests}

The authors declare that they have no competing interests.

Received: 1 September 2021 Accepted: 3 November 2021

Published online: 23 November 2021

\section{References}

1. Hong Kong Government. Oral Health Survey. Hong Kong, 2011. https:// www.toothclub.gov.hk/en/en_pdf/Oral_Health_Survey_2011/Oral_ Health_Survey_2011_WCAG_20141112_(EN_Full).pdf. Accessed 15 May 2021.

2. Hackley DM, Jain S, Pagni SE, Finkelman M, Ntaganira J, Morgan JP. Oral health conditions and correlates: a National Oral Health Survey of Rwanda. Glob Health Action. 2021;14(1):1904628.

3. Kwon SH, Park HR, Lee YM, Kwon SY, Kim OS, Kim HY, et al. Difference in food and nutrient intakes in Korean elderly people according to chewing difficulty: using data from the Korea National Health and Nutrition Examination Survey 2013 (6th). Nutr Res Pract. 2017;11(2):139-46.

4. Wright FAC, Law GG, Milledge KL, Chu SK, Hsu B, Valdez E, et al. Chewing function, general health and the dentition of older Australian men: the Concord Health and Ageing in Men Project. Community Dent Oral Epidemiol. 2019;47(2):134-41.

5. Gonçalves T, Schimmel M, van der Bilt A, Chen J, van der Glas HW, Kohyama K, et al. Consensus on the terminologies and methodologies for masticatory assessment. J Oral Rehabil. 2021:48(6):745-61.

6. Elgestad SP, Sjögren P, Wårdh I, Boström AM. Systematic review of measurement properties of methods for objectively assessing masticatory performance. Clin Exp Dent Res. 2019;5(1):76-104.

7. Hirai T, Ishijima T, Koshino H, Anzai T. Age-related change of masticatory function in complete denture wearers: evaluation by a sieving method with peanuts and a food intake questionnaire method. Int J Prosthodont. 1994; 7(5):454-60.

8. Koshino H, Hirai T, Toyoshita Y, Yokoyama Y, Tanaka M, Iwasaki K, et al. Development of new food intake questionnaire method for evaluating the ability of mastication in complete denture wearers. Prosthodont Res Prac. 2008;7(1):12-8.

9. Limpuangthip N, Somkotra T, Arksornnukit M. Subjective and objective measures for evaluating masticatory ability and associating factors of complete denture wearers: a clinical study. J Prosthet Dent. 2021;125(2):287-93.

10. Murakami M, Watanabe $Y$, Edahiro A, Ohara Y, Obuchi S, Kawai H, et al. Factors related to dissociation between objective and subjective masticatory function in Japanese community-dwelling elderly adults. J Oral Rehabil. 2018;45(8):598-604.

11. Pedroni-Pereira A, Marquezin MCS, Araujo DS, Pereira LJ, Bommarito S, Castelo PM. Lack of agreement between objective and subjective measures in the evaluation of masticatory function: a preliminary study. Physiol Behav. 2018;184:220-5.

12. Santesso N, Barbara AM, Kamran R, Akkinepally S, Cairney J, Akl EA, et al. Conclusions from surveys may not consider important biases: a systematic survey of surveys. J Clin Epidemiol. 2020;122:108-14.

13. Prinsen CA, Vohra S, Rose MR, Boers M, Tugwell P, Clarke M, et al. Guideline for selecting outcome measurement instruments for outcomes included in a Core Outcome Set. The Netherlands: COMET COSMIN; 2016.

14. Prinsen CA, Vohra S, Rose MR, Boers M, Tugwell P, Clarke M, et al. How to select outcome measurement instruments for outcomes included in a "Core Outcome Set"-a practical guideline. Trials. 2016;17(1):1-10.

15. Mokkink LB, De Vet HC, Prinsen CA, Patrick DL, Alonso J, Bouter LM, et al. COSMIN risk of bias checklist for systematic reviews of patient-reported outcome measures. Qual Life Res. 2018;27(5):1171-9.

16. Mokkink LB, Prinsen C, Patrick DL, Alonso J, Bouter LM, De Vet H, et al. COSMIN methodology for systematic reviews of patient-reported outcome measures (PROMs). User manual. 2018; pp. 1-78.

17. Prinsen CA, Mokkink LB, Bouter LM, Alonso J, Patrick DL, De Vet HC, et al. COSMIN guideline for systematic reviews of patient-reported outcome measures. Qual Life Res. 2018;27(5):1147-57.

18. Terwee CB, Prinsen C, Chiarotto A, De Vet H, Bouter LM, Alonso J, et al. COSMIN methodology for assessing the content validity of PROMs-user manual. Amsterdam: VU University Medical Center; 2018.

19. Mittal H, John MT, Sekulić S, Theis-Mahon N, Rener-Sitar K. Patientreported outcome measures for adult dental patients: a systematic review. J Evid Based Dent Pract. 2019;19(1):53-70.

20. Fu L, Liu G, Wu X, Zhu Z, Sun H, Xia H. Patient-reported outcome measures of edentulous patients restored with single-implant mandibular overdentures: a systematic review. J Oral Rehabil. 2021;48(1):81-94.

21. McGrath C, Lam O, Lang N. An evidence-based review of patientreported outcome measures in dental implant research among dentate subjects. J Clin Periodontol. 2012;39:193-201.

22. Yao CJ, Cao C, Bornstein MM, Mattheos N. Patient-reported outcome measures of edentulous patients restored with implant-supported removable and fixed prostheses: a systematic review. Clin Oral Implants Res. 2018:29:241-54.

23. Moher D, Liberati A, Tetzlaff J, Altman DG, the PRISMA Group. Preferred reporting items for systematic reviews and meta-analyses: the PRISMA statement. PLoS Med. 2009;6(7):e1000097.

24. Terwee CB, Mokkink LB, Knol DL, Ostelo RW, Bouter LM, de Vet HC. Rating the methodological quality in systematic reviews of studies on 
measurement properties: a scoring system for the COSMIN checklist. Qual Life Res. 2012;21 (4):651-7.

25. Terwee CB, Bot SD, de Boer MR, van der Windt DA, Knol DL, Dekker J, et al. Quality criteria were proposed for measurement properties of health status questionnaires. J Clin Epidemiol. 2007;60(1):34-42.

26. Khalifa N, Allen PF, Abu-bakr NH, Abdel-Rahman ME. Chewing ability and associated factors in a Sudanese population. J Oral Sci. 2013;55(4):349-57.

27. Miura H, Sato K, Hara S, Yamasaki K, Morisaki N. Development of a masticatory indicator using a checklist of chewable food items for the community-dwelling elderly. Int Sch Res Notices. 2013;2013:194693.

28. Hsu KJ, Lee HE, Wu YM, Lan SJ, Huang ST, Yen YY. Masticatory factors as predictors of oral health-related quality of life among elderly people in Kaohsiung City, Taiwan. Qual Life Res. 2014;23(4):1395-405.

29. Montero J, Dib A, Guadilla Y, Blanco L, Flores J, Gómez-Polo C. Responsiveness of the different methods for assessing the short-term within-subject change in masticatory function after conventional prosthetic treatments. J Prosthet Dent. 2020;123(4):602-10.

30. Fan Y, Shu X, Lo ECM, Leung KCM. Development and validation of a chewing function questionnaire for Chinese older adults. J Dent. 2021:104:103520.

31. Sato Y, Minagi S, Akagawa Y, Nagasawa T. An evaluation of chewing function of complete denture wearers. J Prosthet Dent. 1989;62(1):50-3.

32. Leake JL. An index of chewing ability. J Public Health Dent. 1990:50(4):262-7.

33. Miura H, Araki Y, Hirai T, Isogai E, Hirose K, Umenai T. Evaluation of chewing activity in the elderly person. J Oral Rehabil. 1998;25(3):190-3.

34. Sarita PT, Witter DJ, Kreulen CM, Van't Hof MA, Creugers NH. Chewing ability of subjects with shortened dental arches. Community Dent Oral Epidemiol. 2003:31(5):328-34

35. Zeng X, Sheiham A, Tsakos G. Development and evaluation of an index of eating difficulty for older southern Chinese people. J Oral Rehabil. 2008;35(6):395-401.

36. Baba K, John MT, Inukai M, Aridome K, Igarahsi Y. Validating an alternate version of the chewing function questionnaire in partially dentate patients. BMC Oral Health. 2009;9(1):1-7.

37. Kim B, Jeong S, Chung K, Cho Y, Kwon H, Choi C. Subjective food intake ability in relation to maximal bite force among Korean adults. J Oral Rehabil. 2009:36(3):168-75.

38. Hsu KJ, Lee HE, Lan SJ, Huang ST, Chen CM, Yen YY. Evaluation of a selfassessed screening test for masticatory ability of Taiwanese older adults. Gerodontology. 2012;29(2):e1113-20.

39. Tsuga K, Carlsson G, Österberg T, Karlsson S. Self-assessed masticatory ability in relation to maximal bite force and dental state in 80-year-old subjects. J Oral Rehabil. 1998;25(2):110-6.

40. Cusson V, Caron C, Gaudreau P, Morais JA, Shatenstein B, Payette $H$. Assessing older adults' masticatory efficiency. J Am Geriatr Soc. 2015;63(6):1192-6.

41. Cavalcanti RVA, Junior HVM, de Araújo PL, de Lima KC. Screening for masticatory disorders in older adults (SMDOA): an epidemiological tool. J Prosthodont Res. 2020;64(3):243-9.

42. Khodaeian N, Rismanchian M, Behzadi A, Jowkar F. Validity and reliability of a Persian version of the quality of masticatory function questionnaire for edentulous patients. Dent Res J. 2016;13(2):160

43. Bimbashi V, Staka G, Čelebić A, Hoxha F, Shala K, Petričević N. Psychometric properties of the Albanian version of chewing-function questionnaire CFQ-ALB. Health Qual Life Outcomes. 2016;14:38.

44. Peršić S, Palac A, Bunjevac T, Celebić A. Development of a new chewing function questionnaire for assessment of a self-perceived chewing function. Community Dent Oral Epidemiol. 2013;41(6):565-73.

45. Yanagisawa T, Ueno M, Shinada K, Ohara S, Kawaguchi Y. Validity of selfreported masticatory function in a Japanese population. J Dent Health. 2010:60(3):214-23.

46. Ueno M, Shimazu T, Sawada N, Tsugane S, Kawaguchi Y. Validity of selfreported tooth counts and masticatory status study of a Japanese adult population. J Oral Rehabil. 2018;45(5):393-8.

47. Dougall A, Molina GF, Eschevins C, Faulks D. A Global Oral Health Survey of professional opinion using the International Classification of Functioning. Disability Health J Dent. 2015;43(6):683-94.

48. Mokkink LB, Terwee CB, Patrick DL, Alonso J, Stratford PW, Knol DL, et al. The COSMIN study reached international consensus on taxonomy, terminology, and definitions of measurement properties for healthrelated patient-reported outcomes. J Clin Epidemiol. 2010;63(7):737-45.

49. Crane PK, Gibbons LE, Jolley L, van Belle G. Differential item functioning analysis with ordinal logistic regression techniques DIFdetect and difwithpar. Med Care. 2006:44(11 Suppl 3):S115-123.

50. Petersen MA, Groenvold M, Bjorner JB, Aaronson N, Conroy T, Cull A, et al. Use of differential item functioning analysis to assess the equivalence of translations of a questionnaire. Qual Life Res. 2003;12(4):373-85.

51. Gregorich SE. Do self-report instruments allow meaningful comparisons across diverse population groups? Testing measurement invariance using the confirmatory factor analysis framework. Med Care. 2006;44(11 Suppl 3):S78-94.

52. Teresi JA, Ocepek-Welikson K, Kleinman M, Eimicke JP, Crane PK, Jones $\mathrm{RN}$, et al. Analysis of differential item functioning in the depression item bank from the Patient Reported Outcome Measurement Information System (PROMIS): an item response theory approach. Psychol Sci Q. 2009;51(2):148-80.

53. Cohen J. Statistical power analysis for the behavioral sciences. 2 nd ed. Mahwah: Lawrence Erlbaum Associates; 1988.

54. McHorney CA, Tarlov AR. Individual-patient monitoring in clinical practice: are available health status surveys adequate? Qual Life Res. 1995;4(4):293-307.

55. Norman GR. Issues in the use of change scores in randomized trials. J Clin Epidemiol. 1989;42(11):1097-105

56. Stockler MR, Osoba D, Goodwin P, Corey P, Tannock IF. Responsiveness to change in health-related quality of life in a randomized clinical trial: a comparison of the Prostate Cancer Specific Quality of Life Instrument (PROSQOLI) with analogous scales from the EORTC QLQ-C30 and a trial specific module. J Clin Epidemiol. 1998;51(2):137-45.

57. Altman DG. Practical statistics for medical research. London: Chapman and Hall; 1991.

58. Terwee CB, Prinsen CAC, Chiarotto A, Westerman MJ, Patrick DL, Alonso $J$, et al. COSMIN methodology for evaluating the content validity of patient-reported outcome measures: a Delphi study. Qual Life Res. 2018:27(5):1159-70

59. Streiner DL, Norman G. Health measurement scales: a practical guide to their development and use. Oxford: Oxford University Press; 2008.

60. de Vet HCW, Terwee CB, Mokkink LB, Knol DL. Measurement in medicine: a practical guide. Cambridge: Cambridge University Press; 2011.

\section{Publisher's Note}

Springer Nature remains neutral with regard to jurisdictional claims in published maps and institutional affiliations.

Ready to submit your research? Choose BMC and benefit from

- fast, convenient online submission

- thorough peer review by experienced researchers in your field

- rapid publication on acceptance

- support for research data, including large and complex data types

- gold Open Access which fosters wider collaboration and increased citations

- maximum visibility for your research: over $100 \mathrm{M}$ website views per year

At BMC, research is always in progress.

Learn more biomedcentral.com/submissions 